\title{
Polycyclic Compounds: Ideal Drug Scaffolds for the Design of Multiple Mechanism Drugs?
}

\author{
Cornelis J. Van der Schyf and Werner J. Geldenhuys \\ Department of Pharmaceutical Sciences, Northeastern Ohio Universities Colleges of Medicine and Pharmacy, Rootstown, \\ $\mathrm{OH} 44272$
}

Summary: Recently there has been a resurging interest in developing multi-functional drugs to treat diseases with complex pathological mechanisms. Such drug molecules simultaneously target multiple etiologies that have been found to be important modulators in specific diseases. This approach has significant promise and may be more effective than using one compound specific for one drug target or, by a polypharmaceutical approach, using a cocktail of two or more drugs. Polycyclic ring structures are useful as starting scaffolds in medicinal chemistry programs to develop multi-functional drugs, and may also be useful moieties added to existing structures to improve the pharmacokinetic properties of drugs currently used in the clinic or under development. This review attempts to provide a synopsis of current published research to exemplify the use of polycyclic compounds as starting molecules to develop multi-functional drugs. Key Words: Multifunctional drugs, pentacycloundecane, polycyclic compounds.

\section{INTRODUCTION}

Despite significant advances in drug discovery technologies there remains a significant number of diseases in which challenges exist in finding effective drugs for their treatment or prevention. For example, in the case of neurodegenerative diseases, such as Parkinson's or Alzheimer's disease, multiple etiologies may lead to cell death that is associated with these diseases. Such pathologic multiplicity may account for the difficulty in developing a therapy that may prevent (neuroprotect) damage to, or save (neurorescue) brain cells, since most modern drug development programs are aimed at targeting one specific pathological process in a disease pathway. Therefore, it can be argued that the classic "silver bullet" concept of drug design may have to be reconsidered, and an additional approach added to drug discovery paradigms that can aptly be described as a "magic shotgun" approach.

Recently, there has been a paradigm shift in drug design with a move toward developing multifunctional drugs. ${ }^{1-4}$ There has already been a move by some companies in the pharmaceutical industry to combine two

Address correspondence and reprint requests to: C. J. Van der Schyf, Ph.D., Department of Pharmaceutical Sciences, Northeastern Ohio Universities Colleges of Medicine and Pharmacy, Rootstown, OH 44272. E-mail: cvanders@neoucom.edu. compounds into one formulation, an expansion of the earlier concept inherent in polypharmacy (i.e., administering two or more drugs as separate medicines). Examples include the combination of a $\beta$-adrenergic agonist salmeterol with a steroid fluticasone (Advair, GlaxoSmithKline, London, UK) in the treatment of asthma or combining the cholesterol absorption inhibitor ezetimibe (Zetia, Merck \& Co., Inc., NJ) with the HMG-CoA reductase enzyme inhibitor simvastatin (Zocor, Merck \& Co., Inc.) to render Vytorin (Merck \& Co., Inc./Schering-Plough Corporation, NJ). Conventional wisdom would suggest that the use of a combination medicine may improve patient compliance over traditional polypharmacy, but conversely there may also be an increased risk and even likelihood of introducing more side effects, drug-drug interactions, and exacerbation of drug toxicity. ${ }^{5,6}$ To minimize adverse drug interactions, a drug candidate could be designed as one compound that targets multiple disease mechanisms. These multi-functional ligands may perform better in diseases with complex pathological pathways, in which a one "disease, one drug"3 paradigm has not been met with success. In addition, some multifunctional drugs may work better at normalizing the pathology than a single targeted compound would. For example, the recently introduced "triple" neurotransmitter reuptake inhibitor PRC200 was developed since it was hypothesized that compounds that 

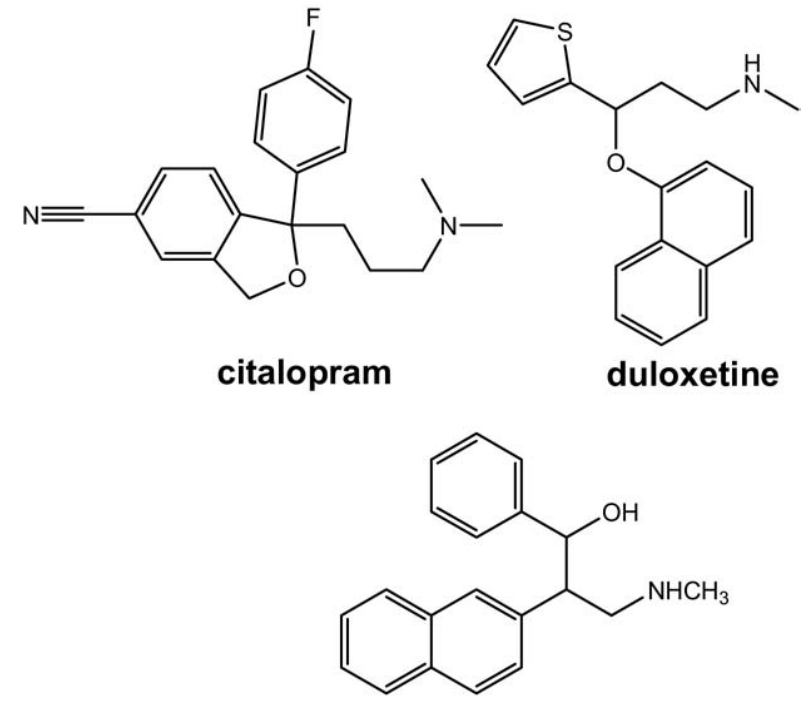

PRC200

FIG. 1. "Single" (citalopram), "dual" (duloxetine), and "triple" (PRC200) neurotransmitter reuptake inhibitors.

simultaneously inhibit serotonin, norepinephrine, and dopamine reuptake into the pre-synaptic terminal may shorten the time required for activity to manifest in patients. These compounds could be more efficacious than the "single" (e.g., citalopram) or "dual" (e.g., duloxetine $^{7}$ ) neurotransmitter reuptake inhibitor approach in the treatment of depression (FIG. 1). ${ }^{8-10}$

An example of a multi-functional drug design program to treat neurodegenerative disease is the development of iron chelators with radical scavenging activity, as well as monoamine oxidase (MAO) inhibition (HLA-20). ${ }^{11,12}$ By combining the antioxidant chelating moiety of 8-hydroxyquinoline of the brain permeable iron chelator VK-28, with the propargyl moiety found in the MAO inhibitors, HLA-20 became a lead compound for neuroprotective studies in Parkinson's disease and Alzheimer's disease pathology (FIG. 2). The reason these compounds seem to have significant benefit in these diseases, can be traced to the role played by iron to generate free radials and reactive oxygen species that precede the death of neurons. ${ }^{13}$ These compounds are therefore neuroprotective by virtue of 1) chelating the iron, and 2) scavenging any free radicals generated in the neuron.

A recent review suggested that there is a significant increase in the publication of reports on multi-functional/ designed multiple ligand drugs in the medicinal chemistry literature surveyed between 1990 and 2004. ${ }^{3}$ This trend may have been initiated by a concurrent surge in neurodegenerative disease and cancer literature, which postulates that these complex diseases may need agents that target disease pathways at multiple points. Although none of these designed drugs have reached the market yet, recent literature suggests this approach to be very promising. 3,4

One question for the medicinal chemist becomes "where to start?" In a review by Morphy and Rankovic, ${ }^{3,4}$ the authors describe mechanisms of designing multifunctional drugs. It is suggested that multifunctional drugs can be designed by starting from a single compound or from two compounds. In the case of the former approach, changes can be made (e.g., functional group changes) that are known to improve activity toward an alternative drug target. The second method entails the consideration of two compounds, each endowed with activity toward the drug targets needed for modulation and conjoining the structures. The simplest way to achieve this combination is by linking the two compounds. As an example, Jacobson et al. ${ }^{14}$ addressed the role of adenosine $A_{1}$ and $A_{3}$ receptors during cardiac ischemia by linking $A_{1}$ and $A_{3}$ adenosine receptor agonists (FIG. 3). Similarly, the group of Scammells published the synthesis of bivalent adenosine $A_{1}$ receptor ligands, and $\beta 2$-adrenergic ligands using a linker system. ${ }^{15}$

Another way of designing multifunctional drugs ${ }^{1,16-22}$ is exemplified by the development of ladostigil $(\text { TV3326) })^{23-27}$ (FIG. 4), which was designed to treat dementia and depression associated with neurodegenerative diseases, such as Alzheimer's disease and Parkinson's disease. The design was derived from the combination of structurally active moieties of the acetylcholine esterase (AChE) inhibitor rivastigmine (i.e., the carbamate) with the monoamine oxidase $\mathrm{B}$ (MAOB) inhibitor deprenyl (a propargylamine). These two structural contributors to the design of ladostigil have both been shown to possess neuroprotective activity in vitro and in vivo. ${ }^{28,29}$

Another question is: "What scaffolds could I start with to generate a congeneric series of compounds for structure-activity relationship studies?" Polycyclic com-<smiles>C#CCN1CCN(Cc2ccc(O)c3ncccc23)CC1</smiles>

HLA20<smiles>OCCN1CCN(Cc2ccc(O)c3ncccc23)CC1</smiles>

VK28
FIG. 2. By combining the antioxidant chelating moiety of 8-hydroxyquinoline of the brain permeable iron chelator VK-28, with the propargyl moiety found in the MAO inhibitors, HLA-20 became a lead compound for neuroprotective studies in Parkinson's disease and Alzheimer's disease pathology. 


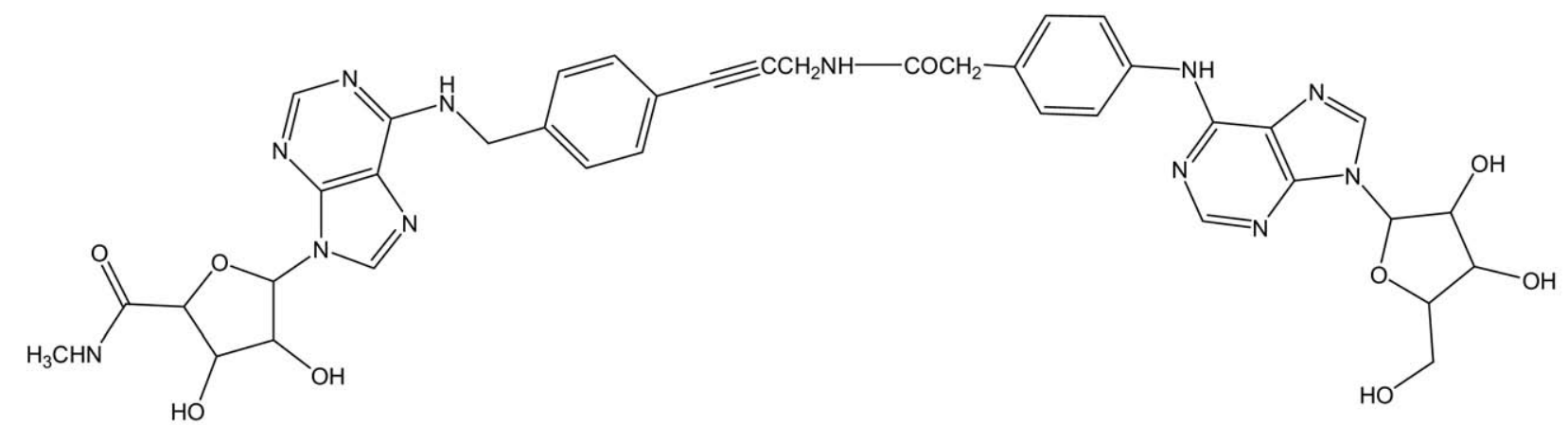

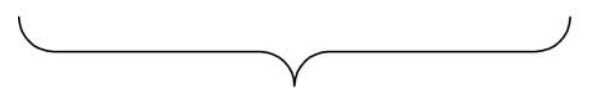

$\mathrm{A}_{3}$-receptor activating moiety

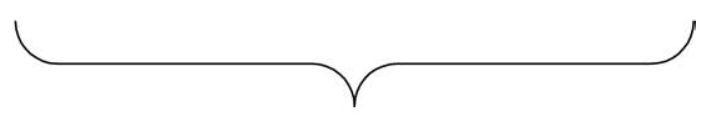

$\mathrm{A}_{1}$-receptor activating moiety

FIG. 3. New dual $A_{1}$ - and $A_{3}$-adenosine receptor agonists developed via a linker. ${ }^{14}$

pounds have been found to be useful scaffolds in chemical structure manipulation in the development of multi-functional drugs. For example, the carbazole ring structure of the antihistamine dimebon has shown promising activity in the treatment of Alzheimer's disease. ${ }^{30,31}$ Although the comprehensive mechanism of the drug still needs to be elucidated, L-type calcium-channel antagonism, NMDA antagonism, and AMPA antagonism may play a part in its multifunctional scope of action. $^{32,33}$

\section{PENTACYCLOUNDECANE AMINES}

The pentacycloundecylamines are polycyclic cage amines derived from reductive amination of Cookson's "bird cage" diketone (FIG. 5, 1). ${ }^{34-37}$ These pentacycloundecylamines have shown to be versatile scaffolds yielding compounds that can target ion channels, second messenger receptors, enzymes, and virus inhibition. ${ }^{38}$ The cage scaffold is derived from the Diels-Alder reaction between $p$-benzoquinone and cyclopentadiene followed by UV photocyclization (FIG. 6). ${ }^{34-37}$

A prominent biologically active pentacycloundecylamine, is NGP1-01 (FIG. 5, 2), which has been shown to be a multifunctional ion-channel blocker. ${ }^{39,40}$ It was first characterized as a voltage-gated calcium-channel blocker in the late 1980s by the group of Van der Schyf. ${ }^{39}$ Initial investigations with NGP1-01 were based on electrophysiological experiments in isolated guineapig papillary muscle and sheep Purkinje fibers. NGP1-01 showed activity that classified this compound as a frequency and voltage-dependent calcium-channel blocker with a mechanism favoring open channel block. Thus, the activity seemed to be related to that of the widely used dihydropyridine calcium-channel blockers, such as nimodipine. NGP1-01 also caused PQ interval prolongation and increased atrioventricular conduction in the heart. Therefore, NGP1-01 may have use in treating heart arrhythmias.

The structure-activity relationships of NGP1-01 derivatives for the voltage-gated calcium-channel blocker were investigated in greater detail. ${ }^{41}$ Whole-cell voltage clamp experiments on guinea pig ventricular myocytes were again used to examine the calcium-channel blocking effects for this set of compounds. Structure-activity relationships (SAR) found in the series appeared to be dominated by geometric or steric constraints rather than by electronic considerations. For example, inhibition of the calcium current was more pronounced with substitutions that occurred in the ortho or meta positions. Para substituted compounds showed similar activity to that of "unsubstituted" NGP1-01. Improved inhibition of the calcium current was observed for compounds with enlarged polycyclic cages (FIG. 5, 3). In addition, molecular modeling studies not only confirmed the observation that size and geometrical conformation (e.g., surface area and volume) are of particular importance for calciumchannel blocking activity, but indicated that electronic characteristics (e.g., molar refractivity and polarizability) should be accounted for as well.

6-Benzylamino-3-hydroxyhexacyclo- $\left[6 \cdot 5 \cdot 0 \cdot 0^{3,7}\right.$. $0^{4,12} \cdot 0^{5,10} \cdot 0^{9,13}$ tridecane (FIG. 5, 3) was characterized when it was evaluated for activity on other ion channels. $^{42}$ Electrophysiological evaluation of 3 (FIG. 5) for potassium and sodium channel blocking was carried out in the guinea pig cardiac papillary muscle. Little selectivity was found toward the ion channels investigated. At the test concentrations used $(10-50 \mu \mathrm{M})$, inhibition of ion current was observed for L-type calcium channels, sodium channels, and the fast component of the delayed rectifier potassium channel. No effects were observed for the T-type calcium channel or for the inward rectifier and slow component of the delayed rectifier potassium chan- 

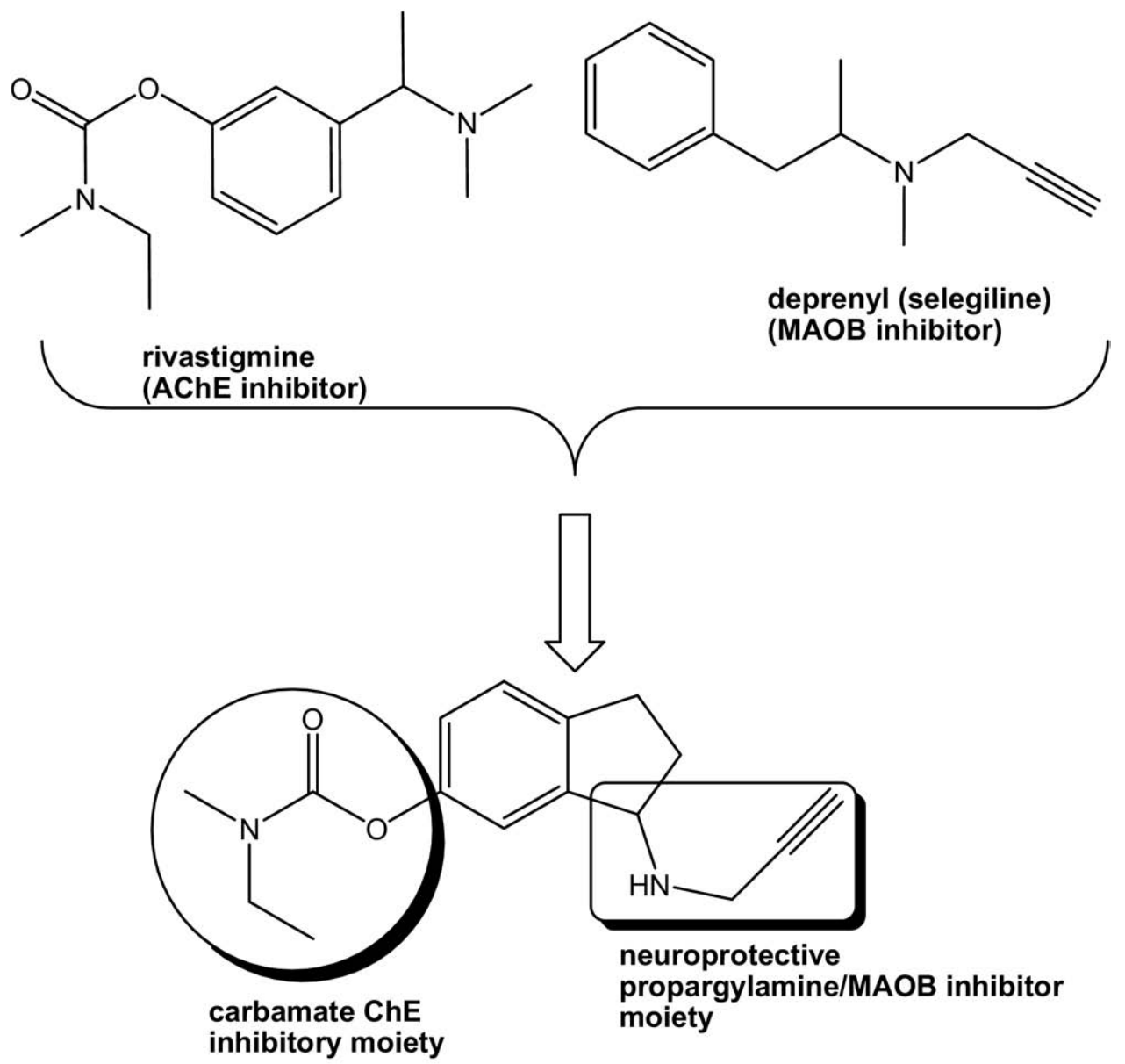

ladostigil

(TV3326)

FIG. 4. Example of the development of a multifunctional drug, ladostigil (TV3326), designed to treat dementia and depression associated with neurodegenerative diseases, such as Alzheimer's disease and Parkinson's disease.

nels. From these data, it was suggested that this compound may have clinical relevance in the treatment of cardiac arrhythmias through its effect on potassium and calcium channels. This conclusion was made based on recent data that suggested that combining potassium and calcium-channel blocking reduces the pro-arrhythmic tendencies of selective class III antiarrhythmic agents. ${ }^{43,44}$ In addition, this compound could have potential in neuroprotective therapy due to antagonism of both the sodium and calcium channels. ${ }^{45}$

Medicinal chemistry intuition led to the investigation of the structural similarity between the polycyclic cage of NGP1-01 and the $N$-methyl-D-aspartate (NMDA) receptor antagonist memantine. ${ }^{46}$ NGP1-01 was therefore screened in a biochemical functional assay to assess NMDA receptor activity. In this study, compounds were evaluated for antagonism of NMDA-mediated ${ }^{45} \mathrm{Ca}^{2+}$ influx into synaptoneurosomes prepared from whole mouse brain. In these experiments NGP1-01 proved to be the most potent compound with an $\mathrm{IC}_{50}$ value of 2.98 $\mu \mathrm{M}$, comparable to that of the reference compound memantine, which had an $\mathrm{IC}_{50}$ value of $3.05 \mu \mathrm{M}$ in the assay used. SAR for aromatic substitution showed that compounds with meta substitution were more active than ortho- and para-substituted derivatives. Similar to other L-type calcium channel antagonists, steric considerations in NMDA receptor antagonism again appeared to be more important than electronic effects. ${ }^{41}$ An increase in the polycyclic cage size from a pentacycloundecane structure to a tridecane structure $\mathbf{3}$ was accompanied by a 10 -fold decrease in potency $(2.98 \mu \mathrm{M}$ for $\mathbf{2}$ vs 36.22 $\mu \mathrm{M}$ for 3) (FIG. 5). This finding suggested that there may be a limitation on the volume of the polycyclic cages to "fit" into the NMDA ion channel pore. Also, data suggested that blockade of the NMDA channel by these compounds was consistent with uncompetitive antagonism, similar to that reported for memantine. It was previously reported ${ }^{47}$ that memantine shares the phencyclidine (PCP)/tenocyclidine (TCP)/MK-801/ketamine binding site inside the NMDA channel pore. Radio-ligand 


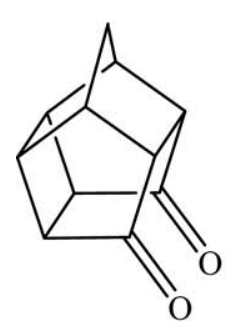

1: Cookson's cage

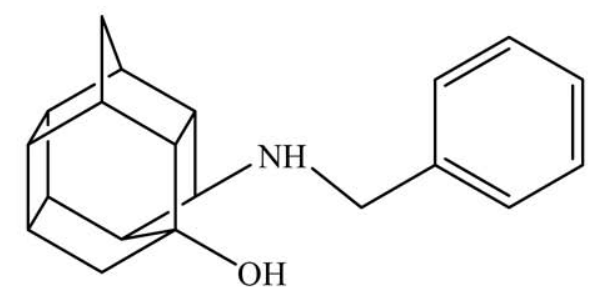

3

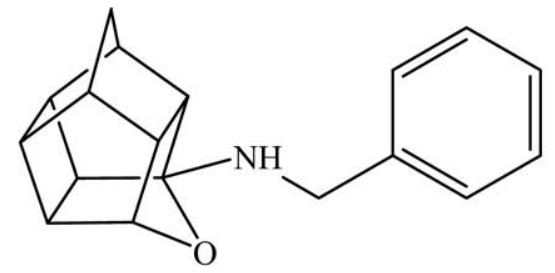

2: NGP1-01

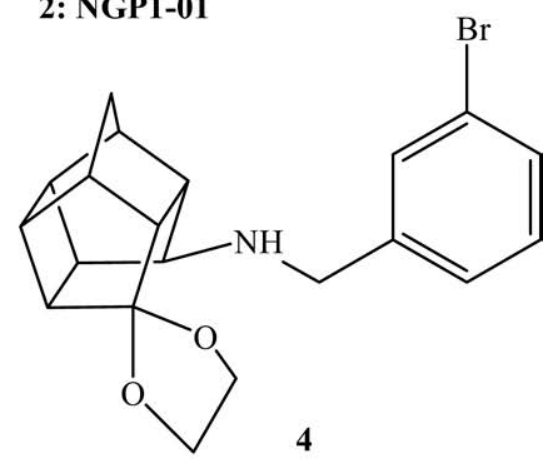

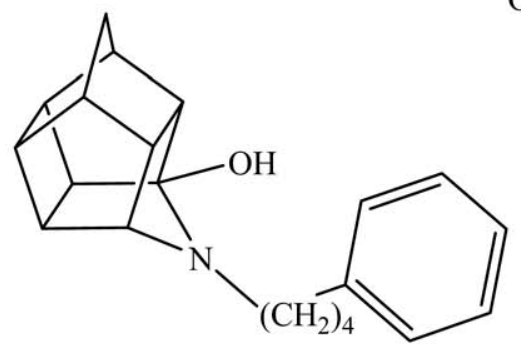

ANSTO-14

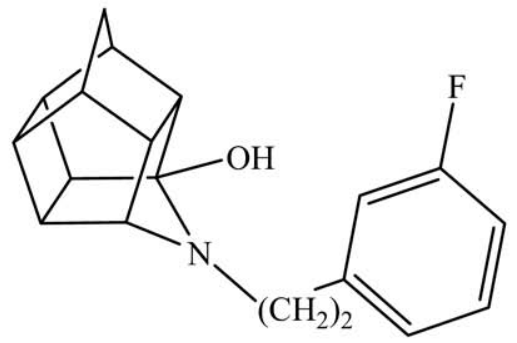

5

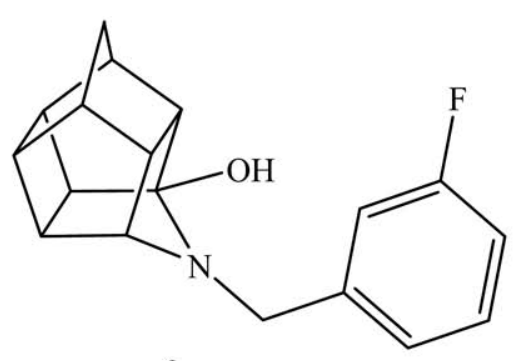

6

FIG. 5. Pentacycloundecylamines.

binding studies with $\left[{ }^{3} \mathrm{H}\right] \mathrm{MK}-801$ and $\left[{ }^{3} \mathrm{H}\right] \mathrm{TCP}$, however, showed little or no displacement of these ligands by the pentacycloundecanes (including NGP1-01). Further studies will have to elucidate the interaction between the cage compounds and the NMDA channel, because the functional block of calcium uptake was observed.

The dual ion-channel blocking activity of NGP1-01 was investigated in vivo and in vitro. ${ }^{40}$ NGP1-01 inhibited depolarization-induced calcium influx by $78 \%$ in cortical neurons preloaded with fura- 2 AM, with a potency similar to that of nimodipine, while simultaneously inhibiting NMDA-induced $(1 \mathrm{mM})$ calcium influx by $52 \%$. This is only slightly less potent than memantine, which was used as a control compound. In vivo microdialysis data showed that choline release during NMDA infusion was consistent with excitotoxic membrane breakdown. Intraperitoneal injection of NGP1-01 (40 $\mathrm{mg} / \mathrm{kg}$ ) reduced NMDA-induced membrane breakdown by $31 \%(p<0.01)$, whereas memantine $(10 \mathrm{mg} / \mathrm{kg})$ reduced choline release by $40 \%$. These results demonstrate that NGP1-01 simultaneously blocks both major neuronal calcium channels and is brain-permeable after peripheral administration. This dual mechanism of modulating calcium entry into neuronal cells might suggest that NGP1-01 may have use as a neuroprotective agent in $\mathrm{AD}$ and other neurodegenerative diseases. Neuroprotective activity for NGP1-01 was recently confirmed in vivo using the middle cerebral artery occlusion mouse model of stroke. It was shown that NGP1-01, administered 30 min before middle cerebral artery occlusion, afforded 

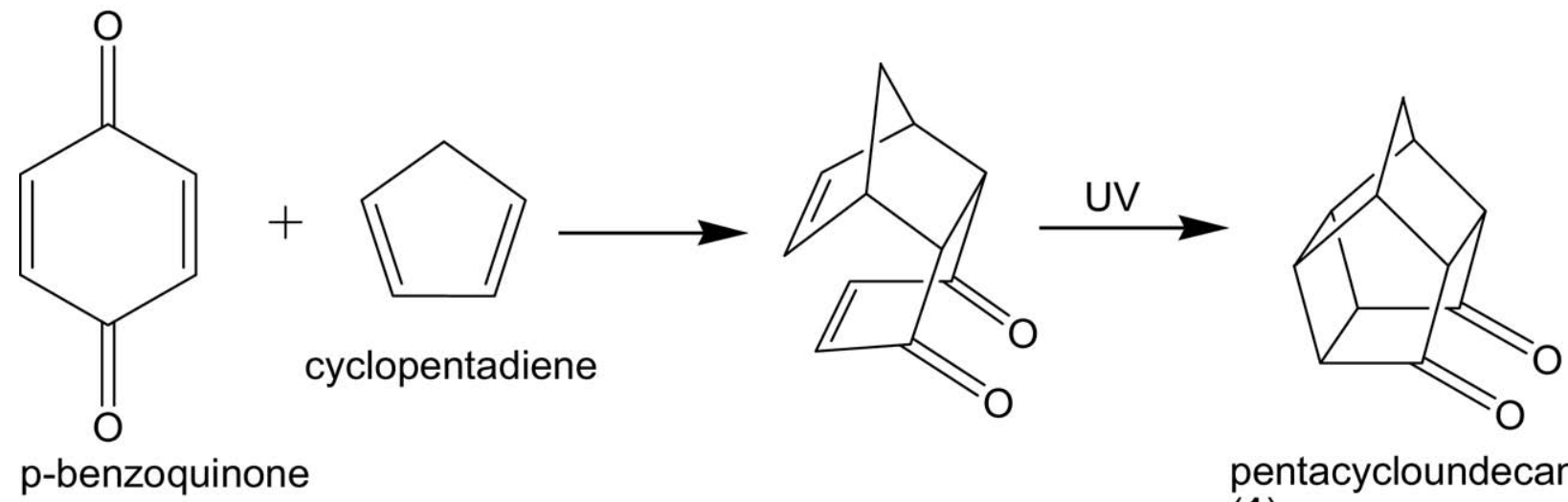

pentacycloundecane

(1)

FIG. 6. The cage scaffold (1) is derived from the Diels-Alder reaction between p-benzoquinone and cyclopentadiene followed by UV photocyclization.

significant protection against cerebral ischemia-induced brain lesioning, as well as brain swelling measured $24 \mathrm{~h}$ after middle cerebral artery occlusion. ${ }^{48}$ These data were also confirmed in a transient model of stroke where treatment was administered up to $48 \mathrm{~h}$ after stroke induction and reperfusion, with similar results. ${ }^{49}$

Protection against a neurotoxin was also evaluated using polycyclic cage amines. ${ }^{50}$ The 1-methyl-4-phenyl1,2,3,6-tetrahydropyridine (MPTP) parkinsonian mouse model has been used extensively to test for neuroprotective agents. ${ }^{51-53} \mathrm{~A}$ small series of pentacycloundecyl amines were administered to C57BL/6 mice at $300 \mathrm{mg} /$ $\mathrm{kg}$, after which MPTP was injected at $35 \mathrm{mg} / \mathrm{kg}$. One of the compounds, the phenylethylamine derivative, showed statistically significant neuroprotection 1 week after MPTP was administered, as determined by measuring dopamine levels in the striatum. MPTP is a pro-toxin, which is converted to its active metabolite $\left(\mathrm{MPP}^{+}\right)$via the enzymatic conversion by monoamine oxidase $\mathrm{B}$ (MAOB). $\mathrm{MPP}^{+}$enters pre-synaptic terminals via the dopamine re-uptake transporter (DAT). To investigate possible mechanisms through which neuroprotection in the MPTP model occurs, the pentacycloundecylamines were evaluated for DAT inhibition (in murine synaptosomes), as well as MAOB inhibition (in baboon liver MAOB). ${ }^{50}$ The phenyl-ethylamine derivative, which showed neuroprotective activity in vivo was able to inhibit dopamine uptake with an $\mathrm{IC}_{50}$ value of $23 \mu \mathrm{M}$. Inhibition of MAOB was observed to be $50 \%$ at $300 \mu \mathrm{M}$. This suggests that DAT inhibition is the likely mechanism by which neuroprotection was afforded in the mouse model.

The polycyclic cage is also a novel scaffold for developing sigma receptor antagonists. Based on data suggesting that the polycyclic cage amantadine binds to the sigma binding site with a $\mathrm{Ki}$ of $20.25 \mu \mathrm{M}$, and memantine with $19.98 \mu \mathrm{M}^{54}$, several pentacycloundecaneamines were assayed for sigma binding. ${ }^{55,56}$ The series consisted of aza-type pentacycloundecylamines, as well as a set containing a secondary amine and a ketal group. Sigma binding for these compounds was shown to range from $17 \mathrm{nM}$ into the high $\mathrm{nM}$ range. Compounds with a secondary amine and ketal moiety seem to prefer binding to the sigma- 1 site versus the sigma- 2 site. The most potent $($ FIG. 5,4$)$ of the series was found to bind with a $\mathrm{Ki}$ of $17 \mathrm{nM}$. For the aza-pentacycloundecanes, one compound (ANSTO-14) was shown to be the most potent with a Ki of $9.4 \mathrm{nM}$. Structure-activity relationships for these compounds suggest that for sigma-1 selectivity, a two-carbon linker between the polycyclic cage and the aromatic ring is preferred, whereas a one-carbon linker is preferred for the sigma-2 binding site. In addition, it appears that meta-position substitution on the aromatic ring is important, especially for the sigma- 2 binding. The effect of meta-position substitution with regard to substituents were found to be $\mathrm{F}>\mathrm{Cl}>\mathrm{Br}>\mathrm{I}>\mathrm{H}>\mathrm{CH}_{3} .{ }^{55,56}$

Some aza-pentacycloundecylamines have been tested in vivo in an effort to develop cocaine addiction therapeutics. ${ }^{57}$ Two meta-fluoro substituted aromatic pentacycloundecylamines (FIG. 5, 5 and 6) were evaluated together with cocaine in behavioral studies with rats. The meta-fluoro phenylethylamine derivative 5 (FIG. 5) showed attenuation of the locomotor stimulating effect of $20 \mathrm{mg} / \mathrm{kg}$ cocaine with an $\mathrm{ID}_{50}$ of $36.5 \mathrm{mg} / \mathrm{kg}$. The study suggested that compound 5 (FIG. 5) acted on the sigma-1 receptor system. In contrast, the meta-fluoro benzylamine derivative (FIG. 5, 6) caused increase in locomotion, with an $\mathrm{ED}_{50}$ of $0.94 \mathrm{mg} / \mathrm{kg}$, and did not attenuate the stimulating effect of cocaine. The findings suggested that compound 6 (FIG. 5) acted on the sigma-2 receptor system. These results corroborate the binding data, which showed compound $\mathbf{6}$ to have selectivity (sigma-1/sigma-2) of 0.03 and compound 5 (FIG. 5), of 7.6.

Furthermore, the aza-pentacycloundecylamines, which have sigma binding affinity, were shown to modulate 

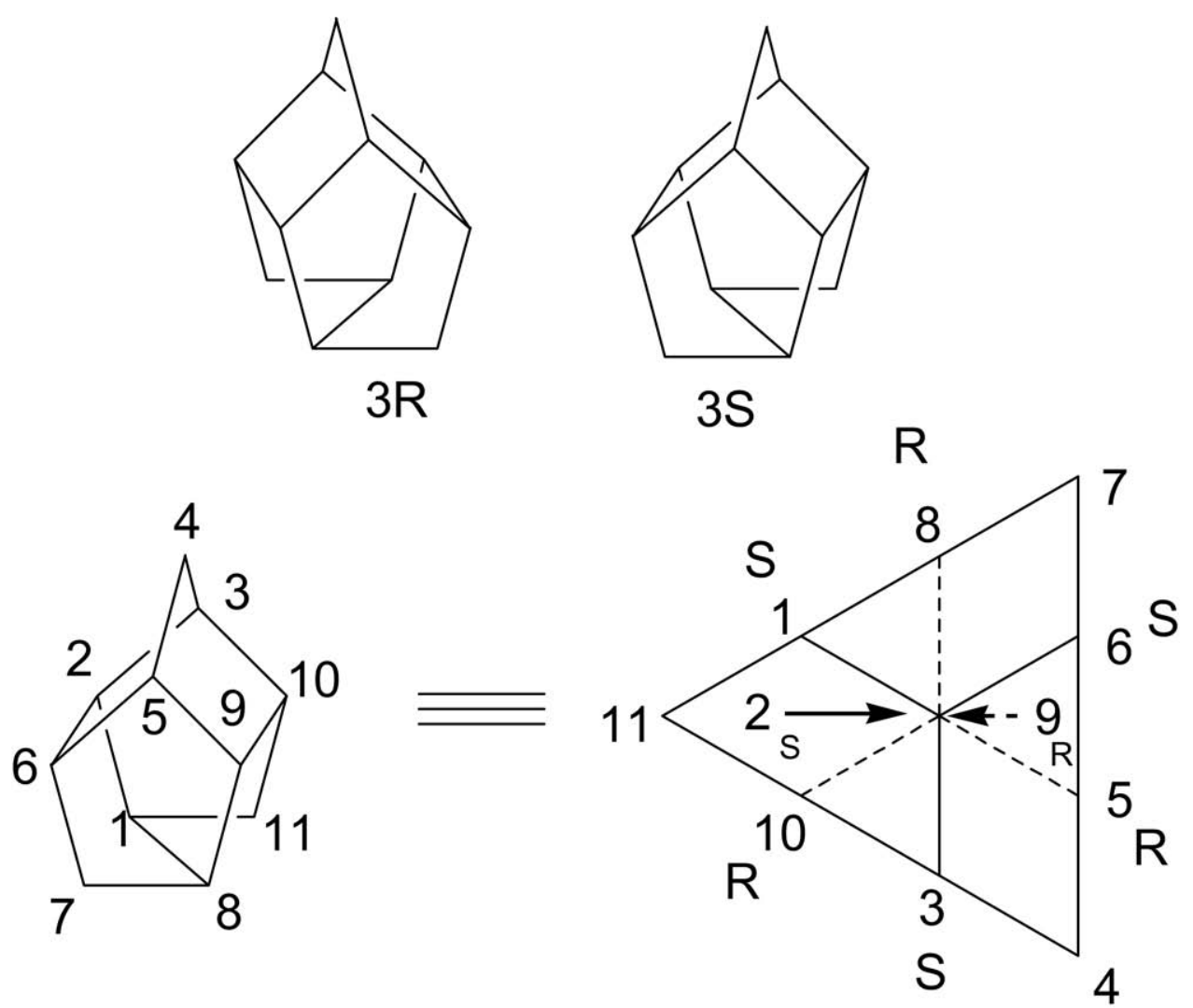

\section{Trishomocubane $\left(D_{3}\right)$ stereochemistry}

FIG. 7. Stereochemistry of the pentacycloundecane stabilomer: $D_{3}$-trishomocubane.

amphetamine-stimulated dopamine release in striatal brain slices, with relatively low binding to the DAT. ${ }^{58}$ This led to the evaluation of compound 5 and $\mathbf{6}$ (FIG. 5) in the 6-hydroxydopamine rat model of Parkinson's disease. For both compounds, a decrease in locomotor activity was seen, which was suggested to indicate sedative or anxiolytic activity. Immunohistochemistry on brain slices with tyrosine hydroxylase as the marker failed to show any neuroprotective activity by these compounds.

\section{TRISHOMOCUBANES}

The trishomocubanes are a unique structure in that they display $\mathrm{D}_{3}$ stereoisomerism (FIG. 7). These "stabilomers" 59 seem to have similar properties as the pen- tacycloundecanes, with the ability to be used for multiple drug targets. In earlier work, trishomocubanes were tested for anti-Parkinson activity. ${ }^{59,60}$ It was found that these compounds showed anti-cataleptic activity in the range of 10 to $34 \mathrm{mg} / \mathrm{kg}$ for $\mathrm{ED}_{50}$, as well as anticholinergic activity in the range of 10 to $100 \mathrm{mg} / \mathrm{kg}$. The control compound for this study, amantadine, was found to exhibit similar activity ranges with an $\mathrm{ED}_{50}$ of 17 and $100 \mathrm{mg} / \mathrm{kg}$ for anti-cataleptic and anti-cholinergic activity, respectively.

In addition to the anti-parkinsonian activity, anti-viral activity was also seen for these compounds. In a study done by Oliver et al., ${ }^{61}$ 4-amino-trishomocubanes displayed anti-viral activity against three different virus

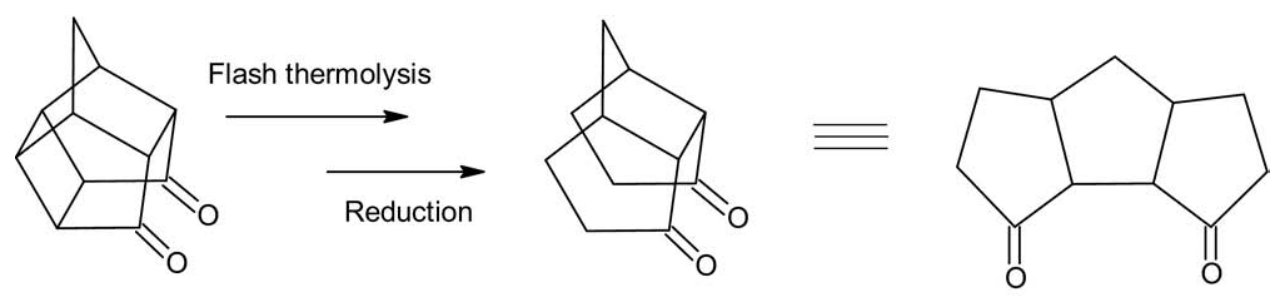

FIG. 8. The triquinyl system is the product of a thermal ring-opening of the pentacycloundecane cage skeleton. 
types, which included Herpes simplex I and II, influenza A2/Taiwan, and the Rhino 1A virus, which were comparable to the control agents amantadine and acyclovir. Liu et al. ${ }^{58}$ evaluated a trishomocubane compound for amphetamine-induced dopamine release and found both DAT binding $(\mathrm{Ki}=623 \mathrm{nM})$ and sigma-1 binding affinity $(\mathrm{Ki}=3 \mu \mathrm{M})$ for this compound.

\section{TRIQUINYL AMINES}

The triquinyl system is the product of a thermal ringopening of the pentacycloundecane cage skeleton. These triquinanes are part of the sesquiterpenoids due to the fused five-member rings (FIG. 8). ${ }^{62}$ After NGP1-01 was found to be a voltage-gated calcium-channel blocker (as previously mentioned), Liebenberg et al. ${ }^{63}$ evaluated the triquinanes for similar activity. The compounds tested were able to suppress the action potential (AP) in guineapig papillary muscle. Clear differences in the side chain were seen, which suggest that these compounds are amenable to SAR studies, with the benzylamine-containing compound completely suppressing the AP, whereas the introduction of an aliphatic side chain resulted in a compound that was only able to suppress the AP by $50 \%$. When a series of amine-triquinane derivatives were screened against $\left[{ }^{3} \mathrm{H}\right]-\mathrm{MK}-801$ binding in murine synaptoneurosomes, a benzylamine derivative showed displacement of $\left[{ }^{3} \mathrm{H}\right]-\mathrm{MK}-801$ with an $\mathrm{IC}_{50}$ value of 1.9 $\mu \mathrm{M}$. This suggests that these compounds may interact with both the voltage-gated calcium channels, as well as the NMDA receptor. ${ }^{64}$

\section{ADAMANTANE AMINES}

The adamantane structure has been of interest to medicinal chemists since the early 1960s when it was introduced to the clinic for the treatment of influenza in the form of amantadine (1-aminoadamantane). The history of the adamantane polycyclic cage in chemistry did not take off until Schleyer ${ }^{65}$ reported a synthetic route to derive these "diamondoids" (adamantane's structure mimicks the lattice structure of diamond). ${ }^{66}$ Although amantadine was first used clinically to treat the influenza virus, serendipitous observation by a clinician led to the observation that Parkinson's disease patients who were treated with amantadine for the flu had improved symptomatology. ${ }^{67}$

Another important polycyclic cage amine, is memantine, an amino-adamantane used to clinically treat Alzheimer's disease. ${ }^{68-71}$ This polycyclic cage amine is an NMDA receptor antagonist. The NMDA receptor is associated with a calcium-ion channel, which when activated by the endogenous excitatory amino acid glutamate, allows the entry of calcium ions into neurons. ${ }^{71}$ Although NMDA receptor antagonists have historically been plagued by an unfavorable side effect profile (e.g., hallucinations from phencyclidine [PCP, "angel dust"]), memantine is well-tolerated due to its fast on-off binding kinetics and uncompetitive antagonism. With uncompetitive antagonism, memantine only blocks calcium flux when the ion channel is in the open state. ${ }^{70}$

Neuronal cell death occurs when excessive stimulation by glutamate leads to excessive influx of calcium ions into neuronal cells. This excess of calcium leads to cell death by inducing apoptotic cell death cascades.$^{69,71} \mathrm{Me}$ mantine's ability to modulate this excitotoxicity via the NMDA receptor is believed to be its major pharmacological mechanism of action in Alzheimer's disease.

Recently it was found that the NMDA receptor can be modulated by S-nitrosylation, whereby excessive activity can be downregulated. ${ }^{69,72}$ These findings led to the synthesis of aminoadamantane nitrates (FIG. 9, 7) envisaging the treatment of neurodegenerative diseases with

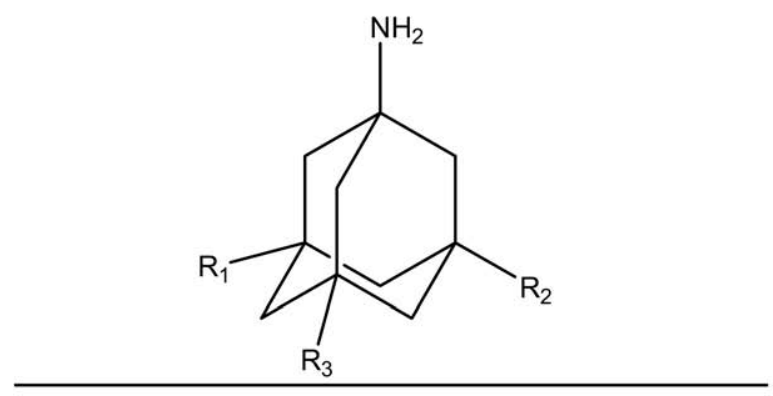

Memantine

$\mathrm{R}_{1}=\mathrm{CH}_{3}$

$\mathrm{R}_{2}=\mathrm{CH}_{3}$
Aminoadamantane nitrates: 7

$\mathrm{R}_{1}=\mathrm{CH}_{3}$ or $\mathrm{CH}_{2} \mathrm{CH}_{3}$

$\mathrm{R}_{2}=\mathrm{CH}_{3}$ or $\mathrm{CH}_{2} \mathrm{CH}_{3}$

$\mathrm{R}_{3}=$ nitrate containing moiety

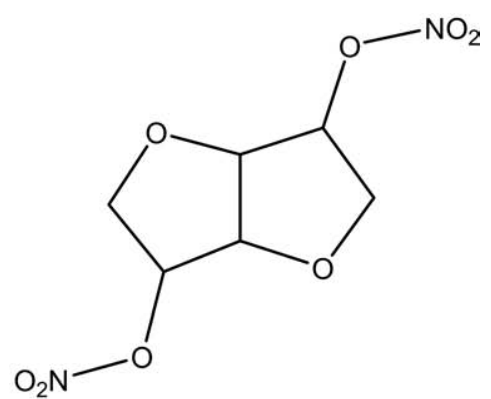

Isosorbide dinitrate: $\mathbf{8}$

FIG. 9. The findings that NMDA receptor can be modulated by S-nitrosylation, whereby excessive activity can be downregulated, ${ }^{69,72}$ led to the synthesis of aminoadamantane nitrates (7). However, the potency found was weaker than the positive control isosorbide dinitrate (8). 

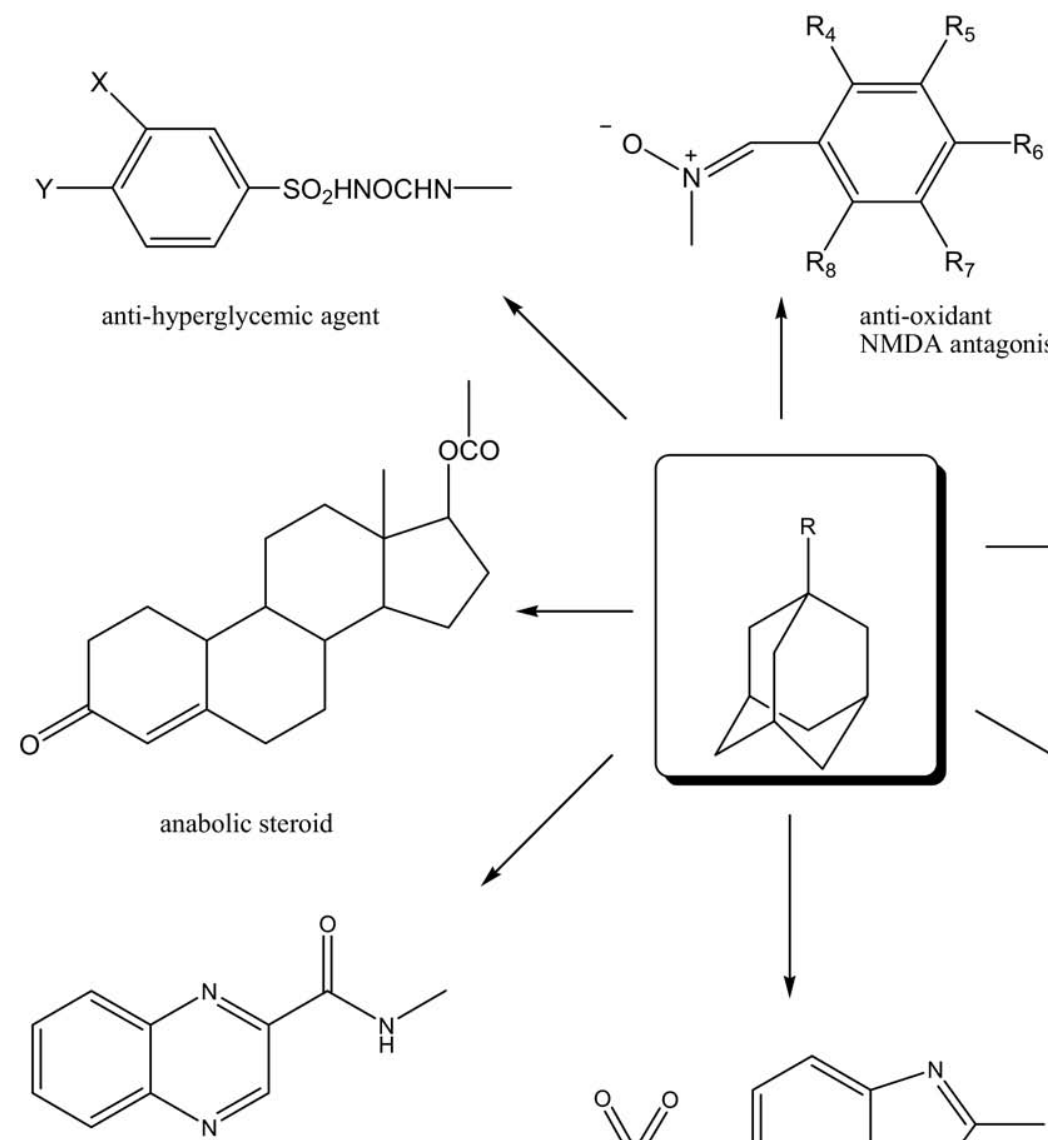

anti-oxidant NMDA antagonist
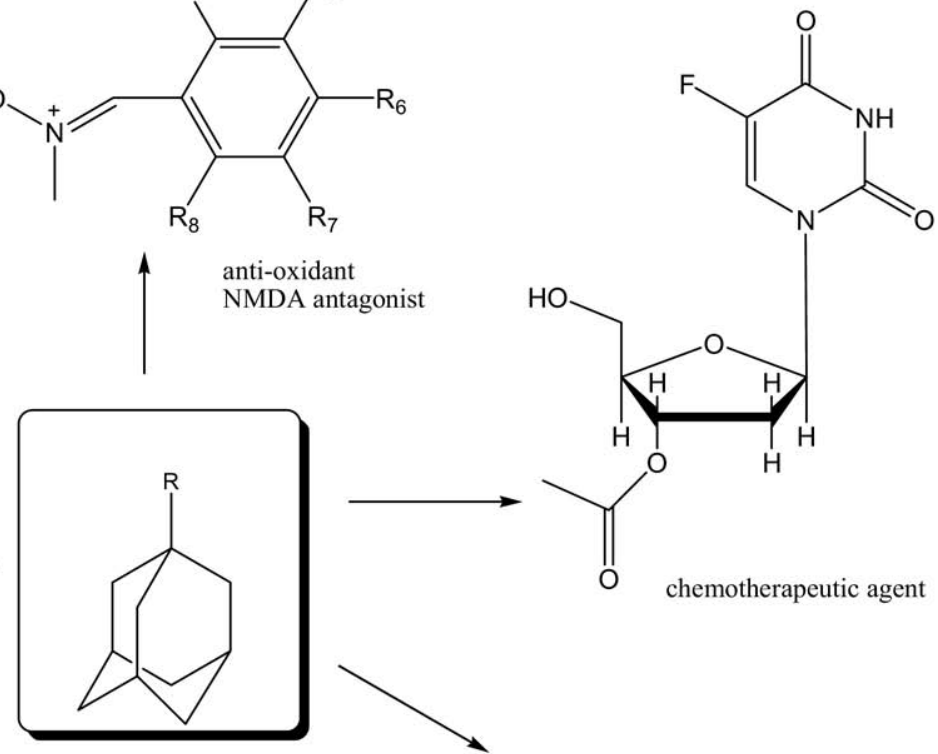

mGlu1 receptor antagonist

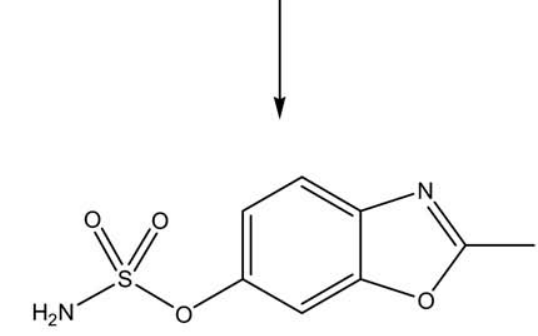<smiles>CCCNC(C)=O</smiles><smiles>CN1CCN(c2ccccn2)CC1</smiles>

anxiolytic antidepressant

steriod sulfatase inhibitor

FIG. 10. The adamantyl moiety has been incorporated in a variety of compounds, which act at various drug targets, ranging from neurotherapeutics to anti-cancer drugs. References are: anti-hyperglycemic ${ }^{76}$; anti-oxidant/NMDA antagonist; chemotherapeutic agent $^{77}$; mGlu1 receptor antagonist ${ }^{78}$; steroid sulfatase inhibitor ${ }^{79}$; anxiolytic/antidepressant. ${ }^{80}$

dual NMDA receptor antagonism, as well as NMDA S-nitrosylation. ${ }^{73}$ Unfortunately, no mention was made of the exact chemical structures of the compounds tested in this study, but it was suggested that the compounds tested were able to antagonize the NMDA receptors and stimulate the release of NO. However, the potency found was weaker than the positive control isosorbide dinitrate (FIG. 9, 8). Additional mention was made suggesting that neuroprotective activity has been observed for these aminoadamantane nitrates (FIG. 9, 7).

From a medicinal chemist's point of view, the adamantyl moiety can be used either as a scaffold for development of therapeutic agents, as can be seen from the examples of memantine and amantadine, or as a modifier of the pharmacokinetics of a compound. In the latter case, the addition of the adamantyl group to carboxylic acids helped decrease cholinesterase hydrolysis. ${ }^{74}$ Another example of where the adamantyl moiety can either be used to increase the lipophilic nature of a compound or add steric bulk has been reported where researchers have attached the adamantyl moiety via an ester bond to the AIDS therapeutic drug zidovudine. This conjugate significantly improved blood-brain barrier penetration of the drug into the CNS. ${ }^{75}$

The adamantyl structure has yielded many compounds in the past 50 years directed toward many different drug targets. FIG. $10^{76-80}$ shows some of the drug targets and drug candidate examples targeting these. A good example of a case in which the addition of the adamantyl group to a compound yielded a candidate compound with a better pharmacokinetic profile was with the discovery of saxagliptin (BMS-477118) (FIG. 11), ${ }^{81}$ which has now entered phase III clinical trials. The $\beta$-quaternary cycloalkylglycine-based inhibitors of dipeptidyl peptidase IV revealed poor bioavailability even though the inhibition of dipeptidyl peptidase IV was potent. By the inclusion of the hydroxyadamantyl moiety to the cyanopyrrolidine, the oral bioavailability dramatically in- 


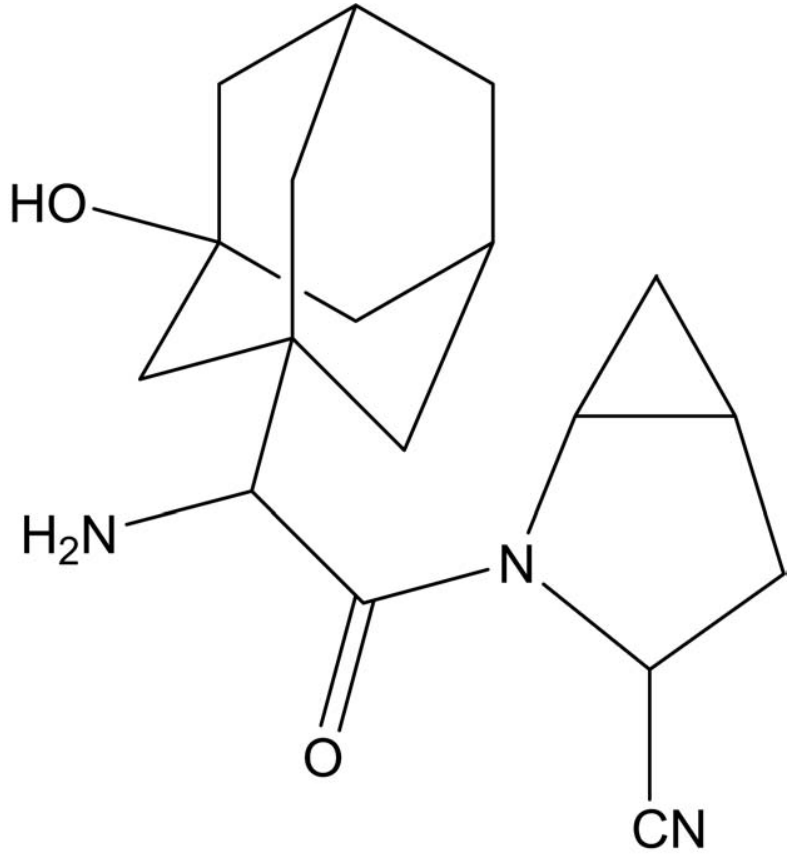

\section{saxagliptin}

FIG. 11. Saxagliptin (BMS-477118) is a good example of a case in which the addition of the adamantyl group to a compound yielded a candidate compound with a better pharmacokinetic profile.

creased (from \pm 5 to $75 \%$ ) while still retaining activity $(\mathrm{Ki}=0.6 \mathrm{nM}){ }^{23-29}$

\section{CONCLUSIONS}

In the recent move to design ligands targeted toward a multitude of sites specific to a particular disease's etiological pathway, several promising new lead compounds have been identified that are able to modulate several of the drug targets. These compounds are more likely to be effective in diseases such as Alzheimer's and Parkinson's disease or in cancers due to the etiological complexity inherent in these diseases. Many drugs with high selectivity to one drug target have not been met with the successes expected in these complex diseases. The polycyclic cage structure seems to be ideally suited for developing multiple mechanism drugs, as it can both serve as a scaffold for the drug molecule proper, or as a moiety that may be added to improve the pharmacokinetic properties of drugs currently used in the clinic, or drug candidates under development.

\section{REFERENCES}

1. Youdim MB, Buccafusco JJ. Multi-functional drugs for various CNS targets in the treatment of neurodegenerative disorders. Trends Pharmacol Sci 2005;26:27-35.

2. Van der Schyf CJ, Gal S, Geldenhuys WJ, Youdim MB. Multifunctional neuroprotective drugs targeting monoamine oxidase in- hibition, iron chelation, adenosine receptors, and cholinergic and glutamatergic action for neurodegenerative diseases. Expert Opin Investig Drugs 2006;15:873-886.

3. Morphy R, Rankovic Z. Designed multiple ligands. An emerging drug discovery paradigm. J Med Chem 2005;48:6523-6543.

4. Morphy R, Kay C, Rankovic Z. From magic bullets to designed multiple ligands. Drug Discov Today 2004;9:641-651.

5. Van der Schyf CJ, Geldenhuys WJ, Youdim MB. Multifunctional neuroprotective drugs for the treatment of cognitive and movement impaired disorders, including Alzheimer's and Parkinson's diseases. Drugs of the Future 2006;31:447-460.

6. Gurwitz JH. Polypharmacy: a new paradigm for quality drug therapy in the elderly? Arch Intern Med 2004;164:1957-1959.

7. Bymaster FP, Beedle EE, Findlay J, et al. Duloxetine (Cymbalta), a dual inhibitor of serotonin and norepinephrine reuptake. Bioorg Med Chem Lett 2003;13:4477-4480.

8. Liang Y, Shaw AM, Boules M, et al. Antidepressant-like pharmacological profile of a novel triple reuptake inhibitor, (1S,2S)-3(methylamino)-2-(naphthalen-2-yl)-1-phenylpropan-1-ol (PRC200SS). J Pharmacol Exp Ther 2008;327:573-583.

9. Shaw AM, Boules M, Zhang Y, et al. Antidepressant-like effects of novel triple reuptake inhibitors, PRC025 and PRC050. Eur J Pharmacol 2007;555:30-36.

10. Carlier PR, Lo MM, Lo PC, et al. Synthesis of a potent widespectrum serotonin-, norepinephrine-, dopamine-reuptake inhibitor (SNDRI) and a species-selective dopamine-reuptake inhibitor based on the gamma-amino alcohol functional group. Bioorg Med Chem Lett 1998;8:487-492.

11. Gal S, Zheng H, Fridkin M, Youdim MB. Novel multifunctional neuroprotective iron chelator-monoamine oxidase inhibitor drugs for neurodegenerative diseases. In vivo selective brain monoamine oxidase inhibition and prevention of MPTP-induced striatal dopamine depletion. J Neurochem 2005;95:79-88.

12. Zheng H, Weiner LM, Bar-Am O, et al. Design, synthesis, and evaluation of novel bifunctional iron-chelators as potential agents for neuroprotection in Alzheimer's, Parkinson's, and other neurodegenerative diseases. Bioorg Med Chem 2005;13:773-783.

13. Zecca L, Youdim MB, Riederer P, Connor JR, Crichton RR. Iron, brain ageing and neurodegenerative disorders. Nat Rev Neurosci 2004;5:863-873.

14. Jacobson KA, Xie R, Young L, Chang L, Liang BT. A novel pharmacological approach to treating cardiac ischemia. Binary conjugates of $\mathrm{A} 1$ and $\mathrm{A} 3$ adenosine receptor agonists. J Biol Chem 2000;275:30272-30279.

15. Karellas P, McNaughton M, Baker SP, Scammells PJ. Synthesis of bivalent beta2-adrenergic and adenosine A1 receptor ligands. J Med Chem 2008;51:6128-6137.

16. Maruyama W, Takahashi T, Youdim M, Naoi M. The anti-Parkinson drug, rasagiline, prevents apoptotic DNA damage induced by peroxynitrite in human dopaminergic neuroblastoma SH-SY5Y cells. J Neural Transm 2002;109:467-481.

17. Maruyama W, Yamamoto T, Kitani K, Carrillo MC, Youdim M, Naoi M. Mechanism underlying anti-apoptotic activity of a (-)deprenyl-related propargylamine, rasagiline. Mech Ageing Dev 2000;116:181-191.

18. Naoi M, Maruyama W, Yagi K, Youdim M. Anti-apoptotic function of L-(-)deprenyl (Selegiline) and related compounds. Neurobiology (Bp) 2000;8:69-80.

19. Naoi M, Maruyama W, Youdim MB, Yu P, Boulton AA. Antiapoptotic function of propargylamine inhibitors of type-B monoamine oxidase. Inflammopharmacology 2003;11:175-181.

20. Youdim MB. The path from anti Parkinson drug selegiline and rasagiline to multifunctional neuroprotective anti Alzheimer drugs ladostigil and m30. Curr Alzheimer Res 2006;3:541-550.

21. Youdim MB, Bakhle YS. Monoamine oxidase: isoforms and inhibitors in Parkinson's disease and depressive illness. Br J Pharmacol 2006;147(suppl 1):S287-296.

22. Youdim MB, Weinstock M. Novel neuroprotective anti-Alzheimer drugs with anti-depressant activity derived from the anti-Parkinson drug, rasagiline. Mech Ageing Dev 2002;123:1081-1086.

23. Bar-Am O, Weinreb O, Amit T, Youdim MB. The novel cholinesterase-monoamine oxidase inhibitor and antioxidant, ladostigil, 
confers neuroprotection in neuroblastoma cells and aged rats. J Mol Neurosci 2008 Aug 27; [Epub ahead of print].

24. Yogev-Falach M, Bar-Am O, Amit T, Weinreb O, Youdim MB. A multifunctional, neuroprotective drug, ladostigil (TV3326), regulates holo-APP translation and processing. Faseb J 2006;20: 2177-2179.

25. Sagi Y, Weinstock M, Youdim MB. Attenuation of MPTP-induced dopaminergic neurotoxicity by TV3326, a cholinesterase-monoamine oxidase inhibitor. J Neurochem 2003;86:290-297.

26. Maruyama W, Weinstock M, Youdim MB, Nagai M, Naoi M. Anti-apoptotic action of anti-Alzheimer drug, TV3326 [(N-propargyl)-(3R)-aminoindan-5-yl]-ethyl methyl carbamate, a novel cholinesterase-monoamine oxidase inhibitor. Neurosci Lett 2003;341: 233-236.

27. Weinstock M, Poltyrev T, Bejar C, Youdim MB. Effect of TV3326, a novel monoamine-oxidase cholinesterase inhibitor, in rat models of anxiety and depression. Psychopharmacology (Berl) 2002;160:318-324

28. Weinstock M, Kirschbaum-Slager N, Lazarovici P, Bejar C, You$\operatorname{dim}$ MB, Shoham S. Neuroprotective effects of novel cholinesterase inhibitors derived from rasagiline as potential anti-Alzheimer drugs. Ann N Y Acad Sci 2001;939:148-161.

29. Weinstock M, Bejar C, Wang RH, et al. TV3326, a novel neuroprotective drug with cholinesterase and monoamine oxidase inhibitory activities for the treatment of Alzheimer's disease. J Neural Transm Suppl 2000:157-169.

30. Bachurin S, Bukatina E, Lermontova N, et al. Antihistamine agent Dimebon as a novel neuroprotector and a cognition enhancer. Ann N Y Acad Sci 2001;939:425-435.

31. Doody RS, Gavrilova SI, Sano M, et al. Effect of dimebon on cognition, activities of daily living, behaviour, and global function in patients with mild-to-moderate Alzheimer's disease: a randomised, double-blind, placebo-controlled study. Lancet 2008;372: 207-215.

32. Lermontova NN, Redkozubov AE, Shevtsova EF, Serkova TP, Kireeva EG, Bachurin SO. Dimebon and tacrine inhibit neurotoxic action of beta-amyloid in culture and block L-type $\mathrm{Ca}(2+)$ channels. Bull Exp Biol Med 2001;132:1079-1083.

33. Grigorev VV, Dranyi OA, Bachurin SO. Comparative study of action mechanisms of dimebon and memantine on AMPA- and NMDA-subtypes glutamate receptors in rat cerebral neurons. Bull Exp Biol Med 2003;136:474-477.

34. Cookson RC, Grundwell E, Hudec J. Synthesis of cage-like molecules by irradiation of Diels-Alder adducts. Chem Ind 1958: 1003-1004.

35. Sasaki T, Eguchi S, Kiriyama T, Hiroaki O. Studies on heterocage compounds-VI transannular cyclizations in pentacyclo [6.2.1.0. $(2,7) 0 .(4,10) 0 .(5,9)]$ undecan-3,6-dione system. Tetrahedron 1974;30:2707-2712.

36. Sasaki T, Eguchi S, Kiriyama T. A facile synthesis of mono-oxaand -aza-bird-cage compounds transannular cyclization. Tetrahedron Lett 1971;12:2651-2654.

37. Marchand AP, Arney BE, Dave PR, Satyanarayana N, Watson WH, Nagl A. Transannular cyclizations in the pentacyclo [5.4.0.02,6.03,10.05,9] undecane-8,11-dione system. A reinvestigation. J Org Chem 1988;53:2644-2647.

38. Geldenhuys WJ, Malan SF, Bloomquist JR, Marchand AP, Van der Schyf CJ. Pharmacology and structure-activity relationships of bioactive polycyclic cage compounds: a focus on pentacycloundecane derivatives. Med Res Rev 2005;25:21-48.

39. Van der Schyf CJ, Squier GJ, Coetzee WA. Characterization of NGP 1-01, an aromatic polycyclic amine, as a calcium antagonist. Pharmacol Res Commun 1986;18:407-417.

40. Kiewert C, Hartmann J, Stoll J, Thekkumkara TJ, Van der Schyf CJ, Klein J. NGP1-01 is a brain-permeable dual blocker of neuronal voltage- and ligand-operated calcium channels. Neurochem Res 2006;31:395-399.

41. Malan SF, Van der Walt JJ, Van der Schyf CJ. Structure-activity relationships of polycyclic aromatic amines with calcium channel blocking activity. Arch Pharm (Weinheim) 2000;333:10-16.

42. Malan SF, Dyason K, Wagenaar B, Van Der Walt JJ, Van Der Schyf CJ. The structure and ion channel activity of 6-benzylamino- 3-hydroxyhexa-cyclo[6.5.0.0(3,7).0(4,12).0(5,10).0(9,13]trid ecane. Arch Pharm (Weinheim) 2003;336:127-133.

43. Thomas D, Wendt-Nordahl G, Rockl K, Ficker E, Brown AM, Kiehn J. High-affinity blockade of human ether-a-go-go-related gene human cardiac potassium channels by the novel antiarrhythmic drug BRL-32872. J Pharmacol Exp Ther 2001; 297:753-761.

44. Nadler G, Faivre JF, Forest MC, et al. Synthesis, electrophysiological properties and analysis of structural requirements of a novel class of antiarrhythmic agents with potassium and calcium channel blocking properties. Bioorg Med Chem 1998;6:1993-2011.

45. O'Neill MJ, Bath CP, Dell CP, et al. Effects of $\mathrm{Ca} 2+$ and $\mathrm{Na}+$ channel inhibitors in vitro and in global cerebral ischaemia in vivo. Eur J Pharmacol 1997;332:121-131.

46. Geldenhuys WJ, Malan SF, Bloomquist JR, Van der Schyf CJ. Structure-activity relationships of pentacycloundecylamines at the N-methyl-d-aspartate receptor. Bioorg Med Chem 2007;15:1525-1532.

47. Bresink I, Danysz W, Parsons CG, Mutschler E. Different binding affinities of NMDA receptor channel blockers in various brain regions-indication of NMDA receptor heterogeneity. Neuropharmacology 1995;34:533-540

48. Mdzinarishvili A, Geldenhuys WJ, Abbruscato TJ, Bickel U, Klein J, Van der Schyf CJ. NGP1-01, a lipophilic polycyclic cage amine, is neuroprotective in focal ischemia. Neurosci Lett 2005;383:49-53.

49. Hao J, Mdzinarishvili A, Abbruscato TJ, et al. Neuroprotection in mice by NGP1-01 after transient focal brain ischemia. Brain Res 2008;1196:113-120.

50. Geldenhuys WJ, Terre'Blanche G, Van der Schyf CJ, Malan SF. Screening of novel pentacyclo-undecylamines for neuroprotective activity. Eur J Pharmacol 2003;458:73-79.

51. Carvey PM, Punati A, Newman MB. Progressive dopamine neuron loss in Parkinson's disease: the multiple hit hypothesis. Cell Transplant 2006:15:239-250.

52. Przedborski S, Tieu K, Perier C, Vila M. MPTP as a mitochondrial neurotoxic model of Parkinson's disease. J Bioenerg Biomembr 2004;36:375-379.

53. Jakowec MW, Petzinger GM. 1-methyl-4-phenyl-1,2,3,6-tetrahydropyridine-lesioned model of Parkinson's disease, with emphasis on mice and nonhuman primates. Comp Med 2004;54:497-513.

54. Kornhuber J, Schoppmeyer K, Riederer P. Affinity of 1-aminoadamantanes for the sigma binding site in post-mortem human frontal cortex. Neurosci Lett 1993;163:129-131.

55. Nguyen VH, Kassiou M, Johnston GA, Christie MJ. Comparison of binding parameters of sigma 1 and sigma 2 binding sites in rat and guinea pig brain membranes: novel subtype-selective trishomocubanes. Eur J Pharmacol 1996;311:233-240.

56. Kassiou M, Nguyen VH, Knott R, Christie MJ, Hambley TW. Trishomocubanes, a new class of selective and high affinity ligands for the sigma binding site. Bioorg Med Chem Lett 1996;6:595600

57. Liu X, Banister SD, Christie MJ, et al. Trishomocubanes: novel sigma ligands modulate cocaine-induced behavioural effects. Eur J Pharmacol 2007;555:37-42.

58. Liu X, Nuwayhid S, Christie MJ, Kassiou M, Werling LL. Trishomocubanes: novel sigma-receptor ligands modulate amphetaminestimulated [3H]dopamine release. Eur J Pharmacol 2001;422: $39-45$.

59. Kent GJ, Godleski SA, Osawa E, Schleyer PvR. Syntheses and relative stability of (D3)-trishomocubane (pentacyclo[6.3.0.02, $6.03,10.05,9]$ undecane), the pentacycloundecane stabilomer. J Med Chem 1977;42:3852-3859.

60. Oliver DW, Dekker TG, Snyckers FO, Fourie TG. Synthesis and biological activity of D3-trishomocubyl-4-amines. J Med Chem 1991;34:851-854.

61. Oliver DW, Dekker TG, Snyckers FO. Antiviral properties of 4-amino-(D3)-trishomocubanes. Arzneimittelforschung 1991;41: $549-552$.

62. Singh V, Thomas B. Recent developments in general methodologies for the synthesis of linear triquinanest. Tetrahedron 1998;54: 3647-3692.

63. Liebenberg W, Van Rooyen PH, Van Der Schyf CJ. The biological activity of two symmetric amine derivatives of the cis-syn-cis triquinane system. Pharmazie 1996;51:20-24. 
64. Bezuidenhout LM, Geldenhuys WJ, Malan SF, Van der Schyf CJ. Polycyclic amine derivatives: The synthesis of triquinylamines as calcium modulators. Poster, American Chemical Society, 233rd National Meeting, Chicago, IL, 2007.

65. Schleyer PvR. A simple preparation of adamantane. J Am Chem Soc 1957;79:3292.

66. Marchand AP. Chemistry. Diamondoid hydrocarbons-delving into nature's bounty. Science 2003;299:52-53.

67. Tilley JW, Kramer MJ. Aminoadamantane derivatives. Prog Med Chem 1981;18:1-44.

68. Lipton SA. Paradigm shift in neuroprotection by NMDA receptor blockade: memantine and beyond. Nat Rev Drug Discov 2006;5: $160-170$.

69. Chen HS, Lipton SA. The chemical biology of clinically tolerated NMDA receptor antagonists. J Neurochem 2006;97:1611-1626.

70. Parsons CG, Danysz W, Quack G. Memantine is a clinically well tolerated N-methyl-D-aspartate (NMDA) receptor antagonist-a review of preclinical data. Neuropharmacology 1999;38:735-767.

71. Kemp JA, McKernan RM. NMDA receptor pathways as drug targets. Nat Neurosci 2002;5(suppl):1039-1042.

72. Choi YB, Tenneti L, Le DA, et al. Molecular basis of NMDA receptor-coupled ion channel modulation by S-nitrosylation. Nat Neurosci 2000;3:15-21.

73. Wang Y, Eu J, Washburn M, et al. The pharmacology of aminoadamantane nitrates. Curr Alzheimer Res 2006;3:201-204.

74. Igumnova ND, Lemina E, Bitiukova II, Klimova NV, Skoldinov AP. [Hydrolysis by plasma cholinesterase of complex adamantylcontaining esters]. Farmakol Toksikol 1988;51:38-41.
75. Tsuzuki N, Hama T, Kawada M, et al. Adamantane as a braindirected drug carrier for poorly absorbed drug. 2. AZT derivatives conjugated with the 1-adamantane moiety. J Pharm Sci 1994; 83:481-484.

76. Gerzon K, Krumkalns EV, Brindle RL, Marshall FJ, Root MA. The Adamantyl Group in Medicinal Agents. I. Hypoglycemic NArylsulfonyl-N' -Adamantylureas. J Med Chem 1963;6:760-763.

77. Gerzon K, Kau D. The adamantyl group in medicinal agents. 3. Nucleoside 5 -adamantoates. The adamantoyl function as a protecting group. J Med Chem 1967;10:189-199.

78. Lavreysen H, Janssen C, Bischoff F, Langlois X, Leysen JE, Lesage AS. [3H]R214127: a novel high-affinity radioligand for the mGlu1 receptor reveals a common binding site shared by multiple allosteric antagonists. Mol Pharmacol 2003;63:1082-1093.

79. Schreiner EP, Wolff B, Winiski AP, Billich A. 6-(2-adamantan-2ylidene-hydroxybenzoxazole)-O-sulfamate: a potent non-steroidal irreversible inhibitor of human steroid sulfatase. Bioorg Med Chem Lett 2003;13:4313-4316.

80. Abou-Gharbia MA, Childers WE, Jr., Fletcher H, et al. Synthesis and SAR of adatanserin: novel adamantyl aryl- and heteroarylpiperazines with dual serotonin 5-HT(1A) and 5-HT(2) activity as potential anxiolytic and antidepressant agents. J Med Chem 1999;42:5077-5094.

81. Augeri DJ, Robl JA, Betebenner DA, et al. Discovery and preclinical profile of Saxagliptin (BMS-477118): a highly potent, longacting, orally active dipeptidyl peptidase IV inhibitor for the treatment of type 2 diabetes. J Med Chem 2005;48:5025-5037. 